\title{
APRESENTAÇÃO
}

Os editores da Revista Augustus apresentam a Edição 54, que traz doze estudos de pesquisadores e professores de diversas instituições de ensino e pesquisa do Brasil. $O$ artigo que abre este número, USO DE PLANTAS MEDICINAIS NAS CIDADES DE CRUZíLIA, SÃO GONÇALO DO SAPUCAÍ E VARGINHA MG, tem como objetivo avaliar o uso de plantas medicinais nos municípios de Cruzília, São Gonçalo do Sapucaí e Varginha MG.

O segundo artigo, DE NORTE A SUL: UMA ANÁLISE SOBRE AS CARACTERÍSTICAS ECONÔMICAS E GASTRONÔMICAS DAS PRINCIPAIS FRUTAS IDENTITÁRIAS NO BRASIL, analisa as características de algumas frutas no território brasileiro, sob a perspectiva do consumo, economia e versatilidade gastronômica. Foram selecionadas as frutas pequi, butiá, jabuticaba, caju e açaí, visto a representatividade de cada uma nas cinco regiões do Brasil.

Dando seguimento, o terceiro trabalho, APROVEITAMENTO DO SILíCIO DERIVADO DA EXTRAÇÃO DO QUARTZITO SÃO THOMÉ NA CULTURA DO PEPINO, mostra que a absorção de silício melhora a eficiência fotossintética das plantas, e que é muito eficiente na proteção de estresses abióticos e bióticos de muitas culturas e pode conferir resistência ao ataque de insetos-praga e nematóides.

O quarto trabalho, AVALIAÇÃO ANTIMICROBIANA DA EFICÁCIA DOS EXTRATOS HIDROALCOÓLICOS DA PITANGUEIRA E DA GOIABEIRA, IN VITRO, CONTRA STAPHYLOCOCCUS AUREUS ISOLADOS DE MASTITE BOVINA, testou a atividade antimicrobiana in vitro por determinação da Concentração Inibitória Mínima (CMI) dos extratos hidroalcoólicos frente às cepas de S. aureus isolados do leite de mastite bovina, e comparar com os antibióticos de uso comum.

O estudo seguinte, ANÁLISE TÉCNICA E ECONÔMICA PARA IMPLANTAÇÃO DE UM CENTRO DE COLETA SELETIVA EM MONSENHOR PAULO - MG, analisou a viabilidade técnica e econômica de implantação de um centro de coleta seletiva no município de Monsenhor Paulo, Sul de Minas Gerais.

POLÍTICA DE PROIBIÇÃO DA DIPIRONA: UMA REFLEXÃO analisa as possíveis reações adversas e toxicidade associadas ao uso da dipirona, bem como a polêmica questão relacionada à sua proibição. 
O sétimo artigo, POSSÍVEIS EVIDÊNCIAS DA VITAMINA B12 NA DOR NEUROPÁTICA: Seria um fator de proteção em Doenças Neurológicas?, discute, por meio de revisão integrativa de literatura, o uso da vitamina B12 associadas às dores neuropáticas.

EDUCAÇÃO AMBIENTAL: DIAGNÓSTICO DOS PROJETOS DESENVOLVIDOS NAS ESCOLAS MUNICIPAIS DE CURITIBA, PR, avaliou os projetos de educação ambiental nas escolas municipais de Curitiba, PR. Foram entrevistadas 35 escolas, divididas em escolas municipais com educação integral, com as séries iniciais e finais.

NARRATIVAS DIGITAIS DE PROFESSORES: UMA REVISÃO SISTEMÁTICA EM TESES E DISSERTAÇÕES BRASILEIRAS realizou uma revisão sistemática de teses e dissertações que tratam de narrativas digitais de professores atuantes em escolas de Educação Básica e Educação Superior no país.

RELAÇÃO COVID-19 X EVASÃO NO ENSINO SUPERIOR LATO SENSU NA MODALIDADE EAD buscou identificar a relação entre casos confirmados de COVID-19 e evasão de alunos nas cidades e regiões brasileiras. A pesquisa trouxe dados sobre a relação COVID-19 x Evasão, relacionados aos números de desempregos no Brasil.

\section{O ENSINO REMOTO EMERGENCIAL E AS LIÇÕES DO NOVO CORONAVÍRUS PARA A SEARA} DA EDUCAÇÃO apresenta reflexões sobre a adoção do ensino remoto emergencial. As narrativas colhidas levaram a um debate pedagógico sobre o lugar da escola e dos estudantes no processo de ensino-aprendizagem.

Por fim, o ESTUDO DE CASO À LUZ DA PSICOLOGIA SÓCIOHISTÓRICA SOBRE O FILME "EXTRAORDINÁRIO": ANÁLISE DA AUTOESTIMA DO PERSONAGEM AUGGIE PULLMAN estudou o processo de construção da autoestima do protagonista Auggie Pullman do filme "O extraordinário", através de uma pesquisa qualitativa, do tipo estudo de caso e baseada na teoria da Psicologia Sócio-histórica.

Desejamos a todos uma boa leitura!

Os Editores. 